limb out of the bath until the current is quite turned off, or he will get a shock; for the same reason the turning off of the current at the close of the treatment must be gradual.

Treatment should be given daily, for half an hour on each occasion.

My experience of the method leads me to recommend it as giving excellent results in all septic wounds and ulcers; it needs no expensive outfit and is painless.

$$
\text { ReFERENCE. }
$$

1 Proceedings of the Royal Society of Medicine, Electro-therapeutic Section, vol. viii, No. 5, p. 45 .

\section{A CASE OF HYSTERICAL AMBLYOPIA.}

BY

KENNETH CAMPBELL, M.B., F.R.C.S., SURGEON TO THE WESTERN OPHTHALMIC HOSPITAL

As acquaintance with a few elementary principles of psychology is necessary for the proper understanding of the modern views concerning hysteria. Up to the time of Locke (1632-1704) the belief was generally held that all ideas are innate-that is, that the mind has the power of spontaneously drawing from its own depths conceptions and ideas which are quite independent of all experience. It was this philosopher who first taught the now generally accepted doctrine that impressions received from without must precede any ideas in the mind, that no ideas exist antecedently to experience. Locke likened the mind at birth to a sheet of white paper upon which the environ ment prints its messages.

There are reasons for thinking that each of us possesses a dual mental life- $(a)$ the ordinary life of normal. conscious thought, and (b) a subconscious mental life (the "subliminal consciousness"). This in effect means that there are two main planes of consciousness-a higher and a lower-and that impulses flowing into the lower plane are not of such degree of intensity as to excite immediate attention, but, being stored up in the mind as memory images, can, under the influence of certain stimuli, enter the higher plane of conscious thought, and thus be presented to the ego. According to Freud, there is no such thing as chance in the determination of a thought, for he postulates that for every psychic phenomenon there has been an antecedent experience in the life-history of the individual. He illustrates this thesis by the following history of a case : A certain young woman complained of the constant presence of the odour of burnt pudding, concerning which she herself could offer no explanation. By applying his method of psycho-analysis Freud eventually was able to trace the hallucination to its source; at a time of great emotional crisis in her life (a repressed love affair) she had been occupied with a burnt pudding.

Alice K., aged 21, exhibits all the classical symptoms of hysteria. She is highly emotional, self-conscious, of defective will power, keenly desirous of sympathy, and speaks in a whisper (hysterical aphonia). Her life has no satisfyin aims.

Visual acuity varies within wide limits. Sometimes it is as low as $\frac{1}{6 r}$; at other times, particularly when her attention is distracted, it is as high as $\frac{6}{6}$. Retinoscopy shows $+2 \mathrm{D}$. of correction. That there is no element of malingering is proved by the fact that she will unintention. ally hurt herself by stumbling over a chair or knockin against a post. Just as visual acuity varies, so does the visual field vary, at times being reduced to a small area around the fixing point. On ophthalmoscopic examination the media are found to be transparent and the fundus normal. There are no signs of disease in any of the viscera. The blood pressure is not raised and the urine is free from albumin. The condition of the kidneys is very important, inasmuch as many cases of amblyopia are uraemic in origin.

Following Freud's method of endeavouring to trace every particular symptom to its source-some antecedent experience in the life-history of the individual-it was revealed that a short time prior to the onset of the visual defect the eyesight of the patient's father had begun to fail. This preyed considerably on her mind, and from then dates the beginning of the amblyopia. Having now traced the condition to its source, the next thing was to get the patient frankly to acknowledge its nature, to face it bravely, and to bring the entire circumstances of it under the criticism of the mind. This line of treatment, com. bined with measures adopted to improve the general health, effected a cure by the end of nine months.

\section{fftemwranda:}

\section{MEDICAL, SURGICAL, OBSTETRICAL.}

\section{HYPOCHLORITE SOLUTIONS IN THE TREATMENT OF WOUNDS.}

Since reading the experimental observations of Professor Lorrain Smith and others on the use of hypochlorous acid as an antiseptic I have used a solution of hypochlorous acid, made by diluting the liquor sodae chlorinatae B.P. with water (one to four of water), extensively in the treatment of industrial injuries in the casualty department of the Bradford Royal Infirmary (at present under my charge). It has exceeded my expectations in every way, although, like many others, I have used it for many years in septic throat conditions with great advantage.

The liquor sodae chlorinatae has the advantage over "eupad" in that it is much more stable, and does not lose its gaseous contents so readily. It is also much more convenient-in civil hospitals, at all events-than the solid "eupad," and its solution is less troublesome to prepare than "eusol"; also its hypochlorous acid content as demonstrated by its power of liberating iodine from a solution of potassium iodide, is greater than that of "eusol." After over twenty years' experience of various antiseptics, I have no hesitation in saying that it is better than any other I know. It is cheaper even than mercury perchloride; it is non-poisonous, is non-irritating to the deep tissues and skin, being almost a neutral solution or only slightly alkaline; it does not either discolour or irritate the surgeon's hands, or destroy his instruments. I have done a number of amputations in badly lacerated hands, where there was every chance of sepsis arising, and even when the full strength of the liquor sodae chlorinatae was used primary union of the flaps was obtained. I have not worked out the lowest effective strength of dilution, but in all probability it can be used effectively in much weaker solution than I have employed. In several cases of previously septic wounds I have used the full strength with most gratifying results. My apology for writing this is that probably many medical men do not realize that they have at hand an old preparation which gives them the benefits of the most recent researches on the antiseptic treatment of wounds when the conditions are such that aseptic methods cannot be applied.

Bradford.

William Mitchell.

\section{LOCALIZATION OF FOREIGN BODIES.}

I HAVE been asked if my "ladder" localizer, described in the British Medical Journal of July 3rd, could not be adapted for the localization of foreign bodies by the fluorescent screen. The following method is quite simple and accurate: With the usual arrangement, the screen above the patient and the tube below, the latter is first set so that the vertical ray is in the plane of the ladder. The shadows of the wire rungs are thus superposed, forming one black line on the screen. This line is marked conveniently by placing over it on the lead glass of the screen a thin knitting needle, with a small piece of adhesive strapping at each end. The shadow of the chosen point of the foreign body is also marked by the point of an ordinary pin; similarly furnished with a bit of strapping. The tube is then moved so that the vertical ray passes through the chosen point of the foreign body. The ladder shadow is now, of course, spread out, the rungs appearing separately. The dividers are next brought into play, one point set on the former shadow of the foreign body (the pin point) and the other on the present shadow. The dividers are then moved to the ladder shadow (the line joining their points being kept parallel to its original direction) and moved along with one point kept lightly pressed against the knitting needle until the second point of the compasses falls on the shadow of a rung, let us say a quarter of the 